\title{
Enhanced Electron Collection Efficiency in Dye-Sensitized Solar Cells Based on Nanostructured $\mathrm{TiO}_{2}$ Hollow Fibers
}

\author{
Elham Ghadiri, ${ }^{\dagger}$ Nima Taghavinia, ${ }^{*}{ }^{\dagger},{ }^{\mp}$ Shaik M. Zakeeruddin, ${ }^{\S}$ Michael Grätzel, ${ }^{\S}$ and \\ Jacques-E. Moser*,
}

${ }^{\dagger}$ Institute for Nanoscience and Nanotechnology and ${ }^{*}$ Physics Department, Sharif University of Technology, Tehran 14588, Iran and ${ }^{\S}$ Institute of Chemical Sciences and Engineering, Ecole Polytechnique Fédérale de Lausanne, CH-1015 Lausanne, Switzerland

\begin{abstract}
Nanostructured $\mathrm{TiO}_{2}$ hollow fibers have been prepared using natural cellulose fibers as a template. This cheap and easily processed material was used to produce highly porous photoanodes incorporated in dye-sensitized solar cells and exhibited remarkably enhanced electron transport properties compared to mesoscopic films made of spherical nanoparticles. Photoinjected electron lifetime, in particular, was multiplied by 3-4 in the fiber morphology, while the electron transport rate within the fibrous photoanaode was doubled. A nearly quantitative absorbed photon-to-electrical current conversion yield exceeding $95 \%$ was achieved upon excitation at $550 \mathrm{~nm}$ and a photovoltaic power conversion efficiency of $7.2 \%$ reached under simulated AM $1.5\left(100 \mathrm{~mW} \mathrm{~cm}^{-2}\right)$ solar illumination.
\end{abstract}

KEYWORDS Dye-sensitized solar cells, $\mathrm{TiO}_{2}$ nanostructured hollow fibers, charge transport, interfacial electron transfer dynamics, transient photovoltage and photocurrent, time-resolved diffuse reflectance

$\mathrm{D}$ ye-sensitized nanocrystalline solar cells (DSC) are of great interest as a cost-effective alternative to conventional silicon photovoltaics. ${ }^{1,2}$ The photoanode in DSC is a mesoporous anatase $\mathrm{TiO}_{2}$ film consisting of interconnected spherical nanoparticles, sensitized by a monolayer of dye molecules. Upon visible light absorption, excited sensitizer molecules inject an electron into the conduction band of $\mathrm{TiO}_{2}$. These carriers are subsequently transported toward and collected by a back-contact electrode. Typical $10 \mu \mathrm{m}$ thick mesoporous films made of $20 \mathrm{~nm}$ diameter particles are characterized by a roughness factor exceeding 1000. Despite the moderate extinction coefficient of Ru(II) polypyridyl dyes used as sensitizers, the large surface area of the nanocrystalline semiconductor allows for the adsorption of enough dye molecules to ensure practically quantitative harvesting of solar light at wavelengths shorter than 600 $\mathrm{nm}$. The use of a light-scattering layer, made of larger $\mathrm{TiO}_{2}$ particles deposited on top of the mesoporous film, further increases the radiation path length within the film and improves in particular the harvesting of red photons. ${ }^{3}$ Further optimization of the photovoltaic performances of the device can be achieved by adjusting the composition of the electrolyte. A certified overall power conversion efficiency of up to $\eta=11.1 \%$ has been achieved so far by optimal devices under AM 1.5 solar illumination. ${ }^{4}$ Dye-sensitized solar cells based on similar $\mathrm{TiO}_{2}$ mesoporous films deprived

\footnotetext{
* To whom correspondence should be addressed. Nima Taghavinia, e-mail, taghavinia@sharif.edu; web, http://ncl.sharif.edu; Jacques-E. Moser, e-mail je.moser@epfl.ch; web, http://photochemistry.epfl.ch.

Received for review: 12/13/2009

Published on Web: 04/27/2010
}

from the large particle light-scattering layer typically exhibit efficiencies of the order of $\eta=7-8 \%$.

Transport of photoinjected electrons in the oxide network to the back contact is believed to occur by diffusion and to be strongly limited by trapping and detrapping within particles and at grain boundaries. ${ }^{5,6}$ This slow electron transport process competes with recombination of carriers with the electrolyte at the surface. The limitation imposed on the electron transport by the mesoporous structure hinders the progress in achieving higher conversion efficiencies. Apparent electron diffusion coefficients, $D_{n}{ }^{*}$, and dynamic electron lifetimes, $\tau_{n}$, in the solid have been shown to predict well the photovoltaic performance of the DSC. Indeed, a majority of photogenerated carriers are collected when the effective diffusion length, $L_{n}$, of electrons is larger than the film thickness, $d$ : $L_{n}=\left(D_{n}{ }^{*} / \tau_{n}\right)^{1 / 2}>d{ }^{7}$ An alternate $\mathrm{TiO}_{2}$ film morphology with improved charge collection efficiency would imply that the trapping of electrons by structural defects such as interparticle connections is minimized, increasing the electron diffusion path length.

One-dimensional nanostructures, such as tubes, wires, and fibers, have recently attracted much attention in research dealing with new morphologies of $\mathrm{TiO}_{2}$ photoactive layers in DSCs. ${ }^{8-15}$ In addition to the potential of improving of electron transport, these nanomaterials provide a large surface area for the adsorption of the dye and also enhance light harvesting efficiency by scattering more light in the red part of the solar spectrum, where the absorption of currently used molecular sensitizers is weak. Among these systems, $\mathrm{TiO}_{(2)}$ nanotube arrays grown perpendicular to the anode substrate gave so far the best results. ${ }^{16-18}$ This particular 
material architecture apparently offers reduced trapping of photoinjected electrons during their path to the back contact. Concomitantly, the redox mediator is expected to diffuse faster in the straight pores and thus transport positive charges more readily than in the tortuous structure characterizing mesoporous layers. DSCs based on vertically aligned nanotubes prepared by anodization of Ti metal, however, suffer generally from a rather low surface area. With an acetonitrile solvent-based electrolyte, a maximum power conversion efficiency of $\eta=6.9 \%$ was recently reached with this $\mathrm{TiO}_{2}$ photoanode morphology. ${ }^{18}$

Here we report on the preparation of $\mathrm{TiO}_{2}$ fibers via a template-based method. Thus obtained hollow microfibers were characterized by a nanostructured, porous surface. They were cast in the form of highly scattering films and used as a photonanode in DSC. When sensitized by a high extinction coefficient Ru(II) complex dye and using a standard $\left(\mathrm{I}_{3}{ }^{-} / \mathrm{I}^{-}\right)$redox mediator-based electrolyte, these systems achieved excellent power conversion efficiencies reaching $\eta=7.2 \%$ under simulated AM 1.5 sunlight irradiation. In similar conditions, where no large particles light scattering layer was used, the photovoltaic performance of devices based on standard layers consisting of spherical nanoparticles was very much comparable, with $\eta=7.3 \%$. Electron transport was scrutinized in both titania fibers and spherical nanoparticle morphologies using transient photovoltage technique. Also, nanosecond transient optical diffuse reflectance spectrometry was applied to opaque fibrous layers to monitor the dynamics of the oxidized dye species at the surface. Results converge in showing a remarkable enhancement of the electron transport efficiency for fibers compared to sintered spherical particle layers, and a near $100 \%$ internal conversion quantum yield for electric current generation.

$\mathrm{TiO}_{2}$ fibers were prepared using cellulose fibers as a template. Cellulose is the most abundant natural polymer. In the form of cotton wool wadding it consists of fibers of a few micrometers in diameter and of typically hundred micrometers length, with a surface area of about $1 \mathrm{~m}^{2} / \mathrm{g}$. It is low cost, ecological, and economically favored for practical applications. Figure 1 schematizes the preparation steps of $\mathrm{TiO}_{2}$ nanostructured fibers. In a typical synthesis, supersaturated aqueous solutions of $\left(\mathrm{NH}_{4}\right)_{2} \mathrm{TiF}_{6}$ (Aldrich) and $\mathrm{H}_{3} \mathrm{BO}_{3}$ (Merck) at $50{ }^{\circ} \mathrm{C}$ were used to deposit $\mathrm{TiO}_{2}$ on cotton fibers (Flawa, oxygen-bleached, hydrophilic, $100 \%$ pure cotton wool). Concentration of the Ti(IV) precursor and the $\mathrm{pH}$ of the solution were adjusted to $0.03 \mathrm{M}$ and 2.0, respectively. In such conditions, the solution supersaturation is low and stepwise hydrolysis and dehydration of $\left(\mathrm{NH}_{4}\right)_{2} \mathrm{TiF}_{6}$ produces $\mathrm{TiO}_{2}$ nanoparticulate films on hydrophilic cellulose fibers through heterogeneous nucleation. The dependence of the conditions of supersaturated solution and the morphology of resultant $\mathrm{TiO}_{2}$ fibers upon synthesis parameters, such as the $\left(\mathrm{NH}_{4}\right)_{2} \mathrm{TiF}_{6}$ concentration, the $\mathrm{pH}$ of the solution and the deposition time, was scrutinized and these results will be

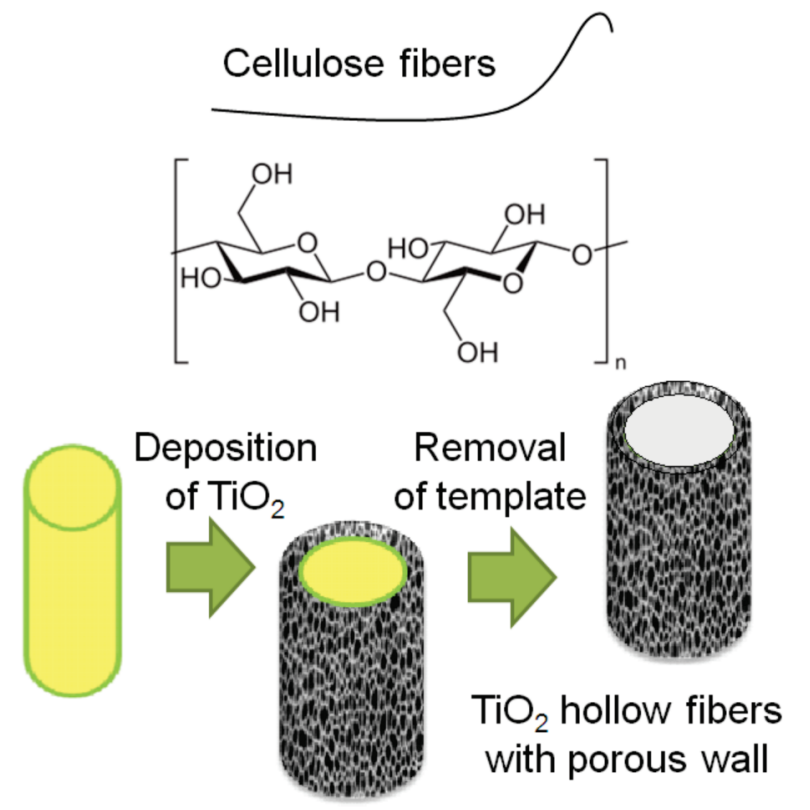

FIGURE 1. Scheme of $\mathrm{TiO}_{2}$ fiber preparation steps.

published elsewhere. After deposition of $\mathrm{TiO}_{2}$ on fibers for $5 \mathrm{~h}$, these were washed with deionized water and dried overnight. The cellulose template was removed by heating the samples at $500{ }^{\circ} \mathrm{C}$ in air for $3 \mathrm{~h}$. Following this recipe all organic material was burnt out and pure $\mathrm{TiO}_{2}$ fibers remained as a result, without significant cross-linking. The morphological aspects of samples and the crystallinity of titania were characterized by scanning electron microscopy (SEM, Phillips XL30) and X-ray powder diffraction (XRD, Bruker, D4 Endeavor) techniques. The specific surface area of $\mathrm{TiO}_{2}$ fibers was determined by BET adsorption-desorption experiments (Belsorp mini II). The measured value of 52 $\mathrm{m}^{2} / \mathrm{g}$ was much larger than that obtained for the cellulose template $\left(1 \mathrm{~m}^{2} / \mathrm{g}\right)$. It implies that the surface of titania hollow fibers is highly nanostructured and offers additional porosity that will be essential for the loading of dye sensitizer molecules.

Nanocrystalline films used to constitute the DSC photoanode were cast on transparent conducting glass using the doctor-blade method. A dispersion of $15 \mathrm{wt} \%$ of $\mathrm{TiO}_{2}$ fibers in water was acidified by $10^{-3} \mathrm{M} \mathrm{HNO}_{3}$ and lightly milled in a mortar. After $1 \mathrm{~h}$ of stirring, the dispersion was treated with a $40 \mathrm{~W}$ ultrasonic titanium probe at a frequency of 15 pulses/s followed by addition of hydroxypropyl cellulose (HPC, MW 20000) at a rate of $20 \%$ (by wt) with respect to $\mathrm{TiO}_{2}$ content and further stirring. The obtained $\mathrm{TiO}_{2}$ paste was doctor-bladed with an automatic moving blade. Prior and after $\mathrm{TiO}_{2}$ coating, the sample was treated with a $40 \mathrm{mM}$ $\mathrm{TiCl}_{4}$ aqueous solution for $30 \mathrm{~min}$ at $70^{\circ} \mathrm{C}$. Finally the titania paste film was heated at $470{ }^{\circ} \mathrm{C}$ in air for approximately 30 min. During this process, the HPC was burnt out and the nanostructured fibers cross-linked together by sintering, yielding a mechanically resistant and opaque film, whose thickness could easily be adjusted from $d=2$ to $10 \mu \mathrm{m}$. 

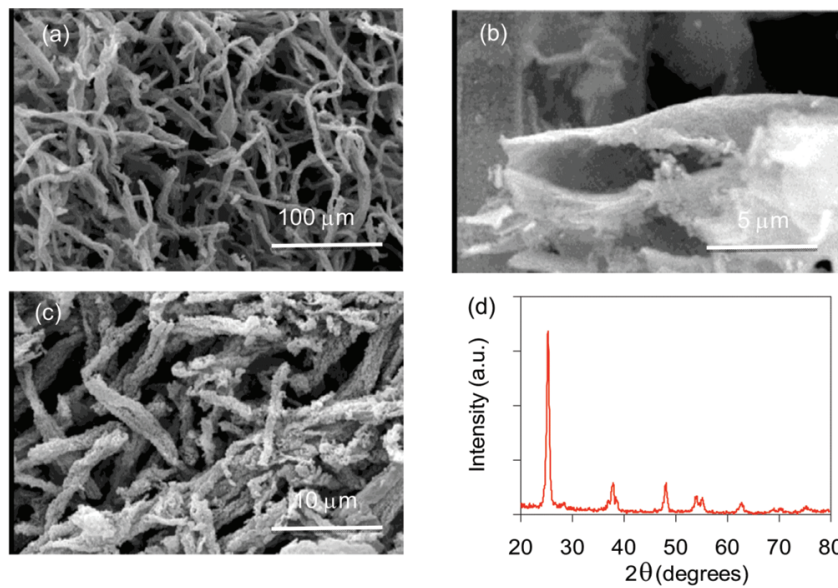

FIGURE 2. (a) SEM micrograph of $\mathrm{TiO}_{2}$ fibers just after the organic template was removed by heat treatment. (b) SEM image showing the cross section of one hollow fiber. (c) Typical SEM image of $\mathrm{TiO}_{2}$ nanofibers obtained after milling and ultrasonication to make a paste. (d) XRD diagrams of the $\mathrm{TiO}_{2}$ fibers.

Scanning electron microscopy (SEM) images of $\mathrm{TiO}_{2}$ microfibers are shown in Figure 2. After initial heat treatment of template-coated fibers, the cellulose was removed yielding $100 \mu \mathrm{m}$ long $\mathrm{TiO}_{2}$ hollow fibers (Figure 2a). A diameter of $1-2 \mu \mathrm{m}$ was estimated for these fibers. The open-end tubular structure of one fiber can be observed in Figure $2 b$. Figure $2 \mathrm{c}$ shows a SEM picture of fibers after they underwent milling and ultrasonication. The latter processes applied during the preparation of the $\mathrm{TiO}_{2}$ paste apparently broke a majority of the fibers to a length of approximately $10-20 \mu \mathrm{m}$. Figure $2 \mathrm{~d}$ shows the X-ray diffraction pattern of the fibers. All the peaks in the XRD pattern can be ascribed to polycrystalline anatase $\mathrm{TiO}_{2}$. Using the Scherrer equation, the average crystalline domain size was estimated to be 11 $\mathrm{nm}$, which is consistent with the nanostructure of the fibers' surface inferred from BET measurements.

Sintered $\mathrm{TiO}_{2}$ fibrous films deposited on conductive glass (NSG10, sheet resistance $10 \Omega \mathrm{sq}^{-1}$ ) were dyed by dipping in $0.3 \mathrm{mM}$ solutions in acetonitrile of the ruthenium complex $\mathrm{Na}-\mathrm{Ru}^{\mathrm{II}}\left(4,4^{\prime}\right.$-bis(5-hexylthiophen-2-yl)-2,2'-bipyridine)(4-carboxylic acid-4'-carboxylate-2, $2^{\prime}$-bipyridine)(NCS) 2 (C101). ${ }^{4}$ This heteroleptic polypyridyl ruthenium(II) complex benefits from enhanced $\pi$-conjugation of the spectator (noncarboxylated) ligand and is characterized by a high molecular extinction coefficient. In conjunction with an acetonitrilebased electrolyte, it has reached already a strikingly high conversion efficiency of $\eta \geq 11.0 \%$. ${ }^{4}$ Test solar cells were then prepared according to a previously described procedure. ${ }^{3}$ The redox-active electrolyte (coded Z960) used throughout the present study consisted of $1.0 \mathrm{M} \mathrm{1,3-dim-}$ ethylimidazolium iodide, $0.05 \mathrm{M}$ LiI, $0.1 \mathrm{M}$ guanidinium thiocyanate, $0.03 \mathrm{M} \mathrm{I}_{2}$, and $0.5 \mathrm{M}$ tert-butylpyridine in a solvent mixture of acetonitrile and valeronitrile $(85 / 15$, v/v).

Dye loading on the surface of $\mathrm{TiO}_{2}$ was quantified by desorbing the dye from the electrode surface in alkaline aqueous medium. The amount of dye adsorbed within $6 \mu \mathrm{m}$

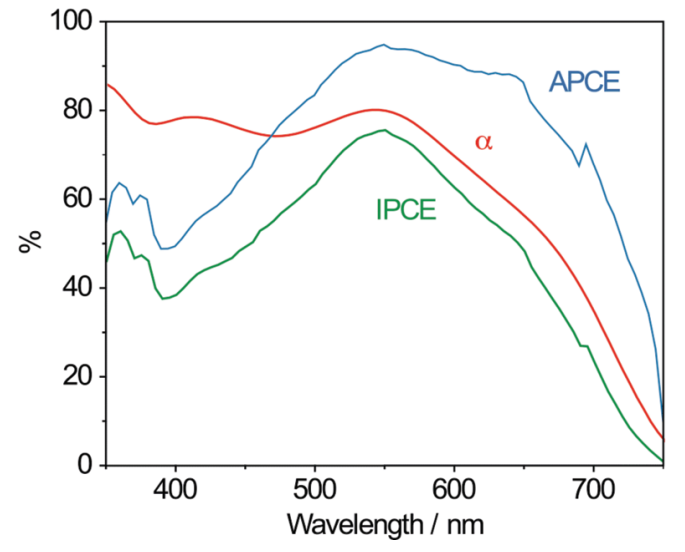

FIGURE 3. Absorptance spectrum $(\alpha)$ calculated from measured diffuse reflectance $\left(R_{\mathrm{d}}\right)$ and diffuse transmittance $\left(T_{\mathrm{d}}\right)$ spectra of a C101 dye-sensitized, $6 \mu \mathrm{m}$ thick film made of $\mathrm{TiO}_{2}$ fibers. The IPCE photocurrent action spectrum was recorded for DSCs based on similar dye-sensitized $6 \mu \mathrm{m}$ thick films. The absorbed photon-tocurrent conversion efficiency $($ APCE $=$ IPCE $/ \alpha$ ) data were finally extracted from the two latter spectra.

thick films made of fibers and spherical nanoparticles was $5.0 \times 10^{-8}$ and $7.1 \times 10^{-8} \mathrm{~mol} / \mathrm{cm}^{2}$, respectively, with regard to the macroscopic geometric area of the $\mathrm{TiO}_{2}$ electrode. Assuming a monolayer dye coverage of $1.04 \times$ $10^{-10} \mathrm{~mol} / \mathrm{cm}^{2}$, the roughness factor of $6 \mu \mathrm{m}$ thick fibrous films was estimated to be $\rho=470$ and, thus, approximately $30 \%$ inferior to that of mesoporous particulate layers of identical thickness, for which a value of $\rho=680$ was calculated. Visible diffuse reflectance $\left(R_{\mathrm{d}}\right)$ and diffuse transmittance $\left(T_{\mathrm{d}}\right)$ spectra of a monolayer of $\mathrm{C} 101$ dye adsorbed on a $6 \mu \mathrm{m}$ thick opaque fiber $\mathrm{TiO}_{2}$ film were measured using a UV-vis spectrophotometer (Varian Cary 5) equipped with an integrating sphere accessory (Figure 3 ). The absorptance $(\alpha)$ of the film, i.e., the fraction of incident light actually absorbed by the dye, is calculated from the relation $\alpha=1$ $-R_{\mathrm{d}}-T_{\mathrm{d}}$. In the blue-green part of the spectrum $(\lambda=$ $400-550 \mathrm{~nm}$ ), absorptance was close to $\alpha=0.8$ and peaked at $\alpha=0.81$ at $\lambda_{\max }=550 \mathrm{~nm}$.

The photocurrent action spectrum of a DSC device made with the same film is shown in Figure 3. The incident photon to current conversion efficiency (IPCE) is given by $\operatorname{IPCE}(\lambda)$ $\left.=U(\lambda) / E_{\text {in }}(\lambda)\right] h c /(e \lambda), \lambda$ being the photon wavelength, $h$ Planck's constant, $c$ the speed of light, $e$ the elementary charge, and $J(\lambda)$ the photocurrent density measured under monochromatic illumination at $\lambda$ with an irradiance $E_{\text {in }}(\lambda)$. This spectrum is clearly far from saturation and peaks at a value of IPCE $=0.77$ at $\lambda=550 \mathrm{~nm}$. From these data, it is inferred that nanostructured fibers solar cells using $6 \mu \mathrm{m}$ thick films, C101 dye sensitizer, and a volatile solvent-based electrolyte are characterized by a conversion quantum yield (absorbed photon-to-current conversion efficiency, APCE), given by $\mathrm{APCE}=\mathrm{IPCE} / \alpha$, exceeding $90 \%$ in the spectral region between 550 and $650 \mathrm{~nm}$. This nearly quantitative conversion yield indicates that adverse recombination processes taking place in the device are actually minimal. 


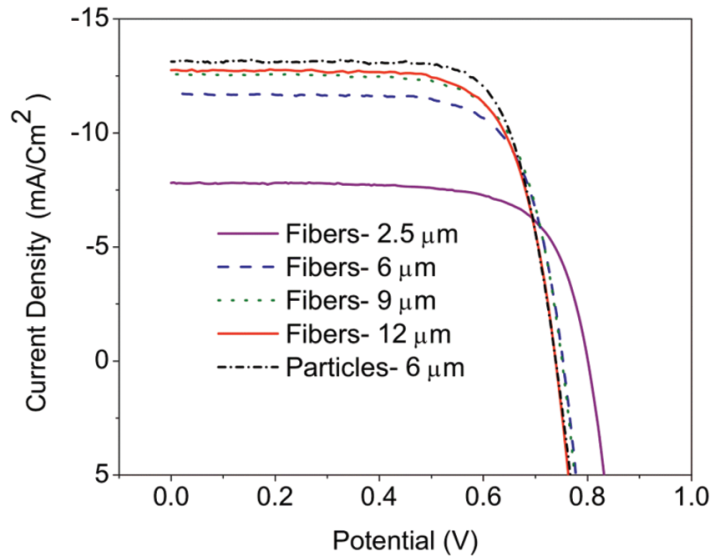

FIGURE 4. $J-V$ characteristics of dye-sensitized solar cells based on fibrous photoanodes of various thicknesses.

TABLE 1. Photovoltaic Parameters of Dye-Sensitized Fiber- and Spherical Nanoparticle-Based Solar Cells with Various Film Thicknesses

\begin{tabular}{lccccc}
\hline anode type & $\begin{array}{c}\text { thickness } \\
(\mu \mathrm{m})\end{array}$ & $V_{\mathrm{OC}}(\mathrm{mV})$ & $J_{\mathrm{SC}}\left(\mathrm{mA} / \mathrm{cm}^{2}\right)$ & FF & efficiency $(\%)$ \\
\hline fibers & 2.5 & 801 & 7.81 & 0.72 & 4.50 \\
& 6 & 760 & 11.63 & 0.73 & 6.47 \\
& 9 & 760 & 13.0 & 0.72 & 7.15 \\
particles & 12 & 746 & 13.2 & 0.73 & 7.13 \\
& 6 & 739 & 13.1 & 0.74 & 7.27
\end{tabular}

Figure 4 shows the photocurrent density-voltage $(J-V)$ characteristics of DSCs prepared with $\mathrm{TiO}_{2}$ fibrous photoanodes of various thicknesses under simulated air mass 1.5 global (AM 1.5G) full sunlight intensity. The setup and method used for such measurements have been previously described. ${ }^{5}$ Detailed photovoltaic parameters, namely, the open-circuit voltage $\left(V_{\mathrm{OC}}\right)$, short-circuit current density $\left(\mathrm{J}_{\mathrm{SC}}\right)$, fill factor (FF), and the photovoltaic power conversion efficiency $(\eta)$ are gathered in Table 1. Comparing devices containing nanostructured fiber-based photoanodes of increasing thickness, the open-circuit voltage $V_{\mathrm{OC}}$ of the DSCs was observed to be reduced as the thickness of the photoactive layer increases. This effect has been generally observed for DSCs based on nanotubes and nanoparticles. ${ }^{14,19}$ It is due to the enhancement of the dark current, which results from the reduction of the electrolyte by conduction band electrons of $\mathrm{TiO}_{2}$. An increase of the film thickness increases the solid-electrolyte contact surface area and hence proportionally the dark current. The excellent fill factor of the $J-V$ characteristic for fibrous $\mathrm{TiO}_{2}$ is quite comparable to the nanoparticulate morphology and does not suffer from the problem generally observed with nanotubes produced by anodization of a metal substrate. A photovoltaic power conversion efficiency of $\eta=4.5 \%$ was achieved with films only $2.5 \mu \mathrm{m}$ thick. The highest efficiency of $\eta=7.15 \%$ was obtained with films of $9 \mu \mathrm{m}$ thickness.

At similar film thickness $(d=6 \mu \mathrm{m})$, Jsc of nanoparticlesbased devices was clearly higher by ca. $1.5 \mathrm{~mA} / \mathrm{cm}^{2}$ than that of the fiber-based cells, whereas $V_{\text {OC }}$ was lower by 21
$\mathrm{mV}$. The reduced current density obtained with fibers can be explained in terms of insufficient light harvesting by dyesensitized films presenting a lower roughness factor and then lower optical absorbance. The higher $V_{\mathrm{OC}}$ has the same cause, as a decreased $\mathrm{TiO}_{2}$ surface area minimizes the dark current.

The performance of a solar cell device is dependent on the kinetic competition between the electron back transfer from the conduction band of $\mathrm{TiO}_{2}\left(\mathrm{e}^{-} \mathrm{cb}\right)$ to the oxidized dye species $\left(\mathrm{S}^{+}\right)$adsorbed on the surface $\left(\mathrm{e}_{\mathrm{cb}}^{-}+\mathrm{S}^{+} \rightarrow \mathrm{S}\right.$, rate constant $k_{\mathrm{b}}$ ) and the dye regeneration process by the iodidebased electrolyte $\left(\mathrm{S}^{+}+2 \mathrm{I}^{-} \rightarrow \mathrm{S}+\mathrm{I}_{2}^{-}\right.$, rate constant $\left.k_{\mathrm{r}}\right)$. Earlier studies performed with nanoparticulate mesoporous $\mathrm{TiO}_{2}$ layers concluded that $\mathrm{e}^{-}{ }_{\mathrm{cb}}-\mathrm{S}^{+}$recombination is controlled to a large extent by trapping and detrapping of electrons at the surface of the oxide and at grain boundaries between spherical particles. ${ }^{5,6}$ In the fibrous morphology, the number of contact points between long fibers, and therefore the number of traps, is expected to be considerably lower than between particles in mesoscopic layers. While $k_{\mathrm{r}}$ is expected to be comparable for both particle- and fiberbased cells, it is then likely that $k_{\mathrm{b}}$ is increased for nanostructured fibers films. Nanosecond transient diffuse reflectance spectroscopy was applied to dye-sensitized, opaque $\mathrm{TiO}_{2}$ fiber layers to study the dynamics of parallel recombination and dye-regeneration reactions. Pulsed excitation $(\lambda$ $=500 \mathrm{~nm}, 5 \mathrm{~ns}$ fwhm pulse duration, $200 \mu \mathrm{J} / \mathrm{cm}^{2}$ pulse energy fluence, $30 \mathrm{~Hz}$ repetition rate) was provided by an optical parametric oscillator (OPO, GWU OPO-355) pumped by a frequency-tripled, Q-switched Nd:YAG laser (Continuum, Powerlite 7030). The laser beam output was expanded by a plano-concave lens to irradiate a large cross section of the sample, whose surface was kept at a $30^{\circ}$ angle to the excitation beam. The probe light, produced by a continuous wave Xe arc lamp, passed through a first monochromator tuned at $\lambda=630 \mathrm{~nm}$ and various optics and was focused onto the sample by the first $6: 1,90^{\circ}$ off-axis ellipsoidal mirror of a modified Praying Mantis (Harrick) diffuse reflection accessory. Diffuse reflected light was collected by the second ellipsoidal mirror, intercepting ca. $20 \%$ of the total reflection at all angles between 0 and $90^{\circ}$ from the surface and was directed to a second monochromator before being detected by a fast photomultiplier tube. Data waves were recorded on a DSA 602A digital signal analyzer (Tektronix). Satisfactory signal-to-noise ratios were typically obtained by averaging over 3000 laser shots.

Assuming the sample was optically thick, diffuse reflectance changes $\Delta R_{\mathrm{d}}$ can be treated using Kubelka-Munk function $^{20}$

$$
F\left(\Delta R_{\mathrm{d}}\right)=\frac{\left(1-\Delta R_{\mathrm{d}}\right)^{2}}{2 \Delta R_{\mathrm{d}}} \propto \varepsilon_{\mathrm{M}} C_{\mathrm{M}}
$$




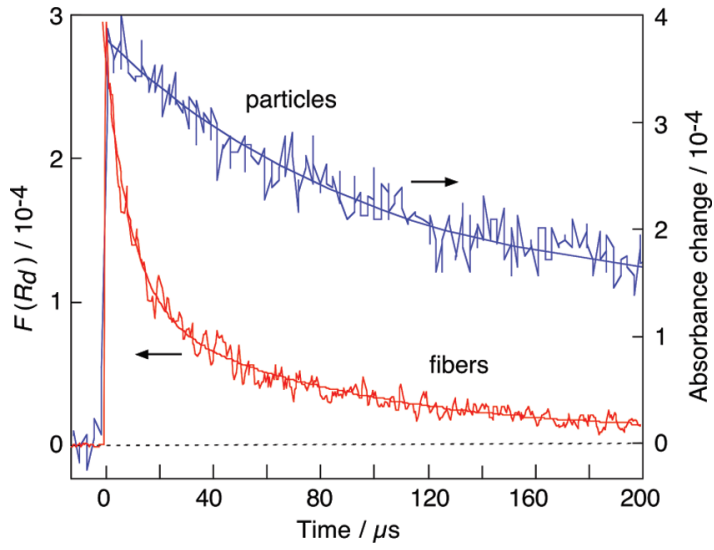

FIGURE 5. Temporal behavior of the Kubelka-Munk function $F\left(\Delta R_{\mathrm{d}}\right)$ of the transient diffuse reflectance measured at $\lambda=630 \mathrm{~nm}$ for a C101 dye-sensitized, $6 \mu \mathrm{m}$ thick, $\mathrm{TiO}_{2}$ fibrous opaque film covered by a redox-inactive ionic liquid upon nanosecond pulsed laser excitation. A typical transient absorbance decay curve obtained in identical conditions with a $8 \mu \mathrm{m}$ thick, dye-sensitized transparent mesoporous $\mathrm{TiO}_{2}$ layer made of $20 \mathrm{~nm}$ diameter spherical particles is shown for comparison.

where $\Delta R_{\mathrm{d}}$ is the reflectance change of the sampled layer, $\varepsilon_{\mathrm{M}}$ the molar decadic extinction coefficient of the absorber, and $C_{\mathrm{M}}$ its molar concentration in the film volume. Figure 5 shows the transient decay of $F\left(\Delta R_{\mathrm{d}}\right)$ recorded at $\lambda=630 \mathrm{~nm}$ for a $\mathrm{C} 101$ dye-sensitized, $6 \mu \mathrm{m}$ thick, opaque $\mathrm{TiO}_{2}$ fiber film covered by a thin film of the redox-inactive ionic liquid 3-methyl-1-ethylimidazolium bis(trifluoromethane)sulfonimide (EMITFSI). The $F\left(\Delta R_{\mathrm{d}}\right.$ ) function (eq 1 ) is proportional to the concentration of the oxidized state $\mathrm{S}^{+}$of dye sensitizer following ultrafast photoinduced electron injection from the excited dye into the conduction band of $\mathrm{TiO}_{2}$. In the absence of a redox electrolyte, the decrease of the signal reflects the dynamics of the recombination of conduction band electrons with the oxidized dye $\mathrm{S}^{+}$. In such conditions, a half reaction time $t_{1 / 2}=18 \mu \mathrm{s}$ was measured.

The observed recombination rate is 1 order of magnitude faster than that in typical mesoporous systems made of sintered spherical particles sensitized by $\mathrm{C} 101$ in similar conditions $\left(t_{1 / 2}=180 \mu \mathrm{s}\right)$. This striking difference indicates that indeed electrons injected in $\mathrm{TiO}_{2}$ nanostructured microfibers experience less trapping than in sintered particles. Rather than being restricted to the volume of one nanocrystalline particle, where they stay in the vicinity of a single oxidized dye molecule, electrons in fibers can also rapidly move to other injection sites, giving rise to a second-order rate kinetics for the recombination reaction and resulting in a marked decrease of $t_{1 / 2}$.

Transient photovoltage measurements were performed to monitor the electron transport dynamics in $\mathrm{TiO}_{2}$ fiber films and to compare it with the behavior of electrons in nanoparticulate films. The method relied on measuring the temporal response of transient open circuit photovoltage upon excitation of the DSCs by a short, low-amplitude red light pulse, superimposed on a steady-state white light irradiation bias. ${ }^{21,22}$ Various intensities of the light bias were

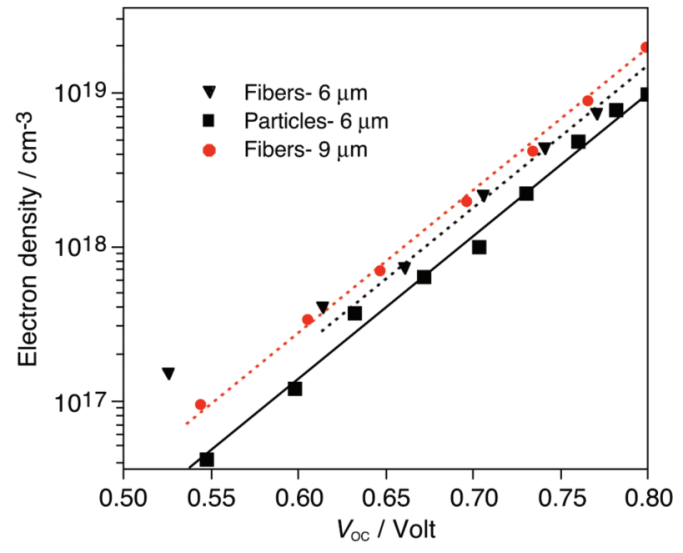

FIGURE 6. Open circuit voltage at different charge density levels for dye-sensitized cells made of $\mathrm{TiO}_{2}$ nanoparticles or fibers.

generated by a white light emitting diode array. Red light pulsed diodes (square wave, $100 \mathrm{~ns}$ rise and fall times, 50 ms pulse duration) controlled by a fast solid-state switch were used as the perturbation source. The voltage dynamics were recorded on a PC-interfaced Keithley 2400 source meter. The pulsed red light intensity was set to a low level to keep the modulated photovoltages values below $10 \mathrm{mV}$. In such conditions the voltage decay dynamics remained monoexponential. When the white light bias intensity is varied, the lifetime $\tau_{\text {rec }}$ characterizing the rate of interfacial charge recombination between conduction band electrons in the $\mathrm{TiO}_{2}$ and the oxidized mediator species $\mathrm{I}_{3}{ }^{-}$in the electrolyte could be estimated from the decay dynamics over a range of biased $V_{\mathrm{OC}}$ values. Besides, the electron transport lifetime $\tau_{\mathrm{n}}$ within the oxide network to the back contact was obtained by recording the rise time of the perturbed open circuit photovoltage. ${ }^{21,22}$ Between each point and before the white LEDs switched to the next intensity, a charge extraction routine was executed by rapidly short circuiting the cell.

The photoinduced electron density in the $\mathrm{TiO}_{2}$ film imposed by the light bias at open circuit, $n\left(\mathrm{~cm}^{-3}\right)$, was estimated from transient photocurrent measurements using the same setup. ${ }^{23}$ The electron density was determined as $n=\Delta Q /[e d(1-p)]$, where $e$ is the elementary charge, $d$ the film thickness, and $p$ the porosity of the oxide material. $\Delta Q$ is the extra charge injected per irradiated surface area during the pulsed excitation. The value of $\Delta Q$ was determined experimentally by integrating the photocurrent density temporal decay at short circuit condition. The density of injected electrons measured at various bias light intensities, is plotted against the corresponding values of the $V_{\mathrm{OC}}$ in Figure 6. The $V_{\mathrm{OC}}$ of fiber DSCs at constant photoelectron density is observed to be $20-30 \mathrm{mV}$ lower than for nanoparticle DSCs. The value of $n$ is indicative of the energy difference between the conduction band edge and the electron quasi-Fermi level under illumination. A lower $V_{\mathrm{OC}}$ at a given value of the photoelectron density can only be attributed to downward movement of the conduction band edge energy. ${ }^{24}$ Since the electrolyte used in both types of 

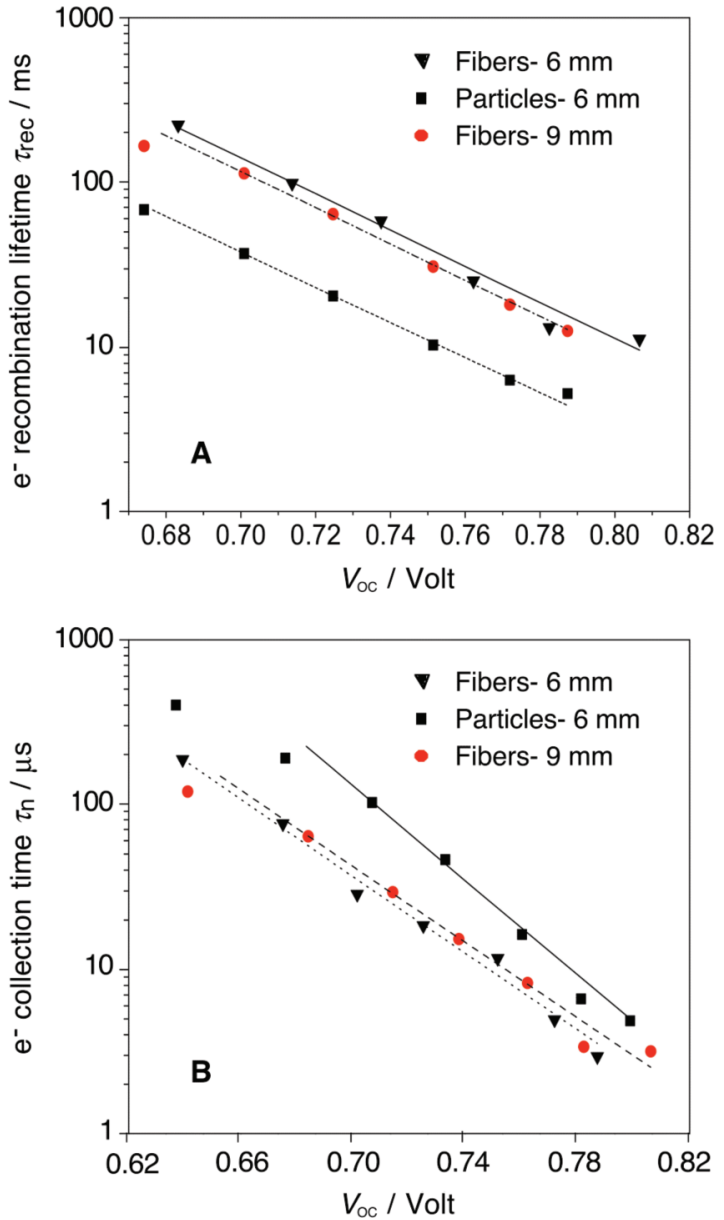

FIGURE 7. (A) Electron recombination lifetime $\tau_{\text {rec }}$ and (B) electron collection time $\tau_{\mathrm{n}}$ extracted respectively from transient open circuit photovoltage decay and rise measurements in fiber- and spherical nanoparticle-based DSCs.

DSCs was identical, the small shift of the conduction band of $\mathrm{TiO}_{2}$ to more positive potentials apparent in fibrous potoanodes can probably be explained by the absence of contamination by $\mathrm{Cl}^{-}$ions that generally characterize nanoparticles prepared from $\mathrm{TiCl}_{4}$ precursor. A somehow lower loading density of the $\mathrm{TiO}_{2}$ surface by the anionic dye $\mathrm{C} 101$ is also likely to contribute to the same effect.

Figure 7 compares recombination $\left(\tau_{\text {rec }}\right)$ and transport $\left(\tau_{\mathrm{n}}\right)$ lifetimes of electrons in $\mathrm{TiO}_{2}$ fiber- and nanoparticle-based DSCs at various light-biased open circuit potentials $V_{\text {OC. }}$ A potential shift of 40-50 $\mathrm{mV}$ was observed between points at comparable $\tau_{\text {rec }}$ values measured in fibrous systems compared to the particulate ones. This $V_{\text {OC }}$ shift is clearly larger than that obtained at constant photoinduced electron density (Figure 6). Thus, for a common film thickness of 6 $\mu \mathrm{m}$, nanostructured fiber-based photoanodes exhibited $\tau_{\text {rec }}$ values about 3 times larger than for nanoparticles at a same charge density. Trapping of carriers was observed from the laser experiments to be reduced in the oxide fibers material and electron transfer rate to the dye oxidized state was apparently accelerated compared to the nanoparticulate situation. Here, however, interfacial charge transfer to the electrolyte is markedly slowed down. This effect is ascribed to the particular morphology of pores surrounding the oxide fibers. Rather than being confined in mesoscopic cavities between nanocrystalline particles, triiodide ions have the possibility to escape faster and farer and to diffuse more freely to the counter electrode. Figure $7 \mathrm{~b}$ compares the electron collection time $\tau_{\mathrm{n}}$ for the two morphologies. Here again, titania fibers appear clearly superior, as they transport electrons to the back contact approximately 2-3 times faster than particles networks. Interestingly, no difference is observed between fibrous photoanodes of 6 and $9 \mu \mathrm{m}$ thickness. This tends to indicate that ca. $10 \mu \mathrm{m}$ long fibers can in both cases transport electrons toward the back contact with a comparable efficiency. $J-V$ curves of Figure 4 show that the unfavorable downward conduction band edge movement is compensated by the slower recombination and that the combined effect of both phenomena corresponds to a net improvement in $V_{\mathrm{OC}}$ of the fibrous DSCs of about $21 \mathrm{mV}$ at constant light intensity.

In conclusion, highly porous photoanodes made of unoriented $\mathrm{TiO}_{2}$ nanostructured hollow fibers show remarkably enhanced electron transport properties compared to mesoporous films made of spherical nanoparticles. The retardation of surface recombination between conduction band electrons and $\mathrm{I}_{3}{ }^{-}$species in the electrolyte observed in nanostructured fiber-based cells is able to offset the adverse shift of the band edge toward positive potential and produce a net open-circuit photovoltage gain of about $21 \mathrm{mV}$. Although still suffering from lower roughness factor and decreased ability to harvest incident light, $\mathrm{TiO}_{2}$ fibers offer obvious advantages that should inspire new developments in the design of improved heterojunction structures in DSC and HOPV applications. The reduced number of contact points between sintered units, which are believed to constitute the main trapping sites for conduction band electrons, as well as the open morphology of pores around the fibers, allowing for a fast diffusion of the electrolyte, are key to the excellent performances achieved with this cheap material. The advent of new stable organic dye sensitizers characterized by higher extinction coefficients ${ }^{25}$ enables sufficient light harvesting with reduced dye loading and, therefore, eases the requirement for a large roughness factor. Further efforts aiming at decreasing the diameter of the fibers and thus increasing the roughness factor of fibrous photoanodes are currently pursued. Application of $\mathrm{TiO}_{2}$ nanostructured hollow fibers in DSCs based on ionic liquids will also be studied. Such solvent-free systems are indeed quite beneficial in terms of stability at high working temperature. The viscosity of the electrolyte in conventional mesoporous cells imposes a limitation to the mass transport at strong light intensity. Photoanodes made of fibrous material characterized by a much lower tortuosity of the pores are then expected to bring a decisive advantage when viscous electrolytes are used. 
Acknowledgment. The authors are grateful to Drs. Robin Humphry-Baker and Mingkui Wang (EPF Lausanne) for experimental help with the transient photovoltage measurements. This work was supported by the Swiss National Science Foundation, under Grant 200020-125163. N.T. and E.G. gratefully acknowledge the financial support of the Iran Ministry of Science, Research, and Technology and of the Research Institute for Petroleum Industry (RIPI).

\section{REFERENCES AND NOTES}

(1) O’Regan, B.; Grätzel, M. Nature 1991, 353, 737-740

(2) Grätzel, M. Nature 2001, 414, 338-344.

(3) Ito, S.; Chen, P.; Comte, P.; Nazeeruddin, M. K.; Liska, P.; Péchy, P.; Grätzel, M. Prog. Photovoltaics 2007, 15, 603-612.

(4) Gao, F.; Wang, Y.; Shi, D.; Zhang, J.; Wang, M.; Jing, X.; HumphryBaker, R.; Wang, P.; Zakeeruddin, S. M.; Grätzel, M. J. Am. Chem. Soc. 2008, 130, 10720-10728

(5) Haque, S. A.; Tachibana, Y; Willis, R. L.; Moser, J. E.; Grätzel, M.; Klug, D. R.; Durrant, J. R. J. Phys.Chem. B 2000, 104, 538-547.

(6) Nelson, J.; Chandler, R. E. Coord. Chem. Rev. 2004, 248, $1181-$ 1194. (c) Nelson, J. Phys. Rev. B 1999, 59, 15374-15380.

(7) Wang, Q.; Moser, J. E.; Grätzel, M J. Phys. Chem. B 2005, 109, 14945-14953.

(8) Song, M. Y.; Kim, D. K.; Ihn, K. J.; Jo, S. M.; Kim, D. Y. Nanotechnology 2004, 15, 1861-1865

(9) Fujihara, K.; Kumar, A.; Jose, R.; Ramakrisna, S.; Uchida, S Nanotechnology 2007, 18, 365709.

(10) Chuangchote, S.; Sagawa, T.; Yoshigawa, S. Appl. Phys. Lett. 2008, 93, No. 033310
(11) Jose, R.; Kumar, A.; Thavasi, V.; Ramakrishna, S. Nanotechnology 2008, 19, 424004-424011

(12) Mukherjee, K.; Teng, T. H.; Jose, R.; Ramakrisna, S. Appl. Phys. Lett. 2009, 95, No. 012101

(13) Enach-Pommer, E.; Liu, B.; Aydil, E. S. Phys. Chem. Chem. Phys. 2009, 11, 9648-9652.

(14) Kuang, D.; Brillet, J.; Chen, P.; Takata, M.; Uchida, S.; Miura, H.; Sumioka, K.; Zakeeruddin, S. M.; Grätzel, M. ACS Nano 2008, 2, $1113-1116$.

(15) Zhu, K.; Neale, N. R.; Miedaner, A.; Frank, A. J. Nano Lett. 2007, 7, 69-74

(16) Mor, G. K.; Shankar, K.; Paulose, M.; Varghese, O. K.; Grimes, C. A. Nano Lett. 2006, 6, 215-218.

(17) Feng, X.; Shankar, K.; Varghese, O. K.; Paulose, M.; Latempa, T. J.; Grimes, C. A. Nano Lett. 2008, 8, 3781-3786.

(18) Varghese, O. K.; Paulose, M.; Grimes, C. A. Nat. Nanotechnol. 2009, 4, 592-597.

(19) Kuang, D. B.; Ito, S.; Wenger, B.; Klein, C.; Moser, J. E.; HumphryBaker, R.; Zakeerudddin, S. M.; Grätzel, M. J. Am. Chem. Soc. 2006, $128,4146-4154$

(20) Kubelka, P.; Munk, Z. Z. Tech. Phys. 1931, 12, 593-601.

(21) O'Regan, B. C.; Durrant, J. R. J. Phys. Chem. B 2006, 110, 85448547

(22) Barnes, P. R. F.; Liu, L.; Li, X.; Anderson, A. Y.; Kisserwan, H.; Ghaddar, T. H.; Durrant, J. R.; O’Regan, B. C. Nano Lett. 2009, 9 , 3532-3538.

(23) Zhang, Z.; Zakeeruddin, S. M.; O’Regan, B. C.; Humphry-Baker, R.; Grätzel, M. J. Phys. Chem. B 2005, 109, 21818-21824.

(24) Kopidakis, N.; Neale, N. R.; Frank, A. J. J. Phys. Chem. B 2006, 110, 12485-12489.

(25) Grätzel, M. Acc. Chem. Res. 2009, 42, 1788-1798. 